\title{
Executive functioning in three groups of pupils in D-KEFS: Selected issues in adapting the test battery for Slovakia ${ }^{1}$
}

\section{Jan Ferjenčík, Miriam Slavkovská, Juraj Kresila}

Abstract: The paper reports on the adaptation of a D-KEFS test battery for Slovakia. Drawing on concrete examples, it describes and illustrates the key issues relating to the transfer of test items from one socio-cultural environment to another. The standardisation sample of the population of Slovak pupils in the fourth year of primary school included 250 children with an average age of 9.7 years. The two comparative samples of the same age range were analysed at the same time. They included pupils from classes for gifted children $(n=55)$ and Roma children from socially disadvantaging environments $(n=50)$.

The results manifested a significant skewness in most distributions of the D-KEFS primary indicator raw scores. The nature of the skewness suggests that these indicators are more sensitive at discriminating the performance of weaker children but not at discriminating within the above-average performance range. The distribution in the Roma children sample was skewed to the opposite value. Most of the Roma children found the tests from the D-KEFS battery, especially those based on verbal materials, too difficult and so it only differentiated results achieved by the best in the group. Comparisons of the mean scores in all the primary indicators (One-way ANOVA) highlight the need to establish specific norms for the standard population of Slovak children on the one hand and for Roma children from socially disadvantaging environment on the other.

Keywords: Delis-Kaplan, executive functions, test adaptation.

This work was supported by the Slovak Research and Development Agency under grant number APVV0281-11. 
Low academic achievement in children naturally inspires us to seek out the possible cause. One of the standard hypothetical answers, often formulated by teachers and school psychologists, is that low academic achievement is mainly a result of insufficient levels of intelligence in addition to inadequate motivation. Although empirical findings have frequently lent support to this supposition (Butler et al., 1985; Brody, 1997, 1999; Jensen, 1998; Keith, 1999), it is of little practical use in education. If test results show that a child has subnormal intelligence this does not provide the teacher with the tools to work effectively with the child. Diagnostics of this nature label rather than solve the child's actual problems. Performance in any standard intelligence test is, in fact, the result of activating and integrating the many cognitive processes involved in solving a specific task. The same score attained in the test of intelligence by two pupils can thus be determined by entirely different configuration of strengths and weaknesses in cognitive functioning of these children. In view of this, broadening the scope of educational and psychological diagnostics by adding executive function tests may prove both appealing and useful. The term "executive function" (central executive) was first used in science by Baddeley and Hitch in 1974 in an attempt to highlight not only the importance of the end results but also the way in which the human mind achieves these results and the processes it uses to do so. Lezak (1983), who followed up on these ideas, conceptualized executive functioning as a system consisting of four main components: goal setting, planning, carrying out goal-directed plans, and effective performance. The ensuing popularity of research exploring executive functions resulted in a number of definitions and models differing in both the number and nature of the components as well as in the ways in which they are measured (Duncan et al., 1996 Godefroy et al., 1999; Miyake et al, 2000; Elliot, 2003; Barkley, Russell, 2012). Despite this divergence, there is consensus on the notion that executive functions constitute a group of variables that control, direct and supervise the cognitive processes involved in the process beginning from setting specific goals to their attainment (McCloskey et al, 2008). The variables mentioned most frequently in this regard include planning, cognitive flexibility, inhibition and working memory.

Existing research on executive functions predominately looks at how they relate to neurobiological factors. A number of studies examine the correlates of executive functioning in different types of organic brain damage caused by trauma, congenital impairments or developmental dementia (Stussy, A1exander, 2000; Rapp, Reisch, 2005; Dillon, Pizzagalli, 2007; Anderson et al., 2008; Koven, Thomas, 2010; Stussy, 2011). Some research examin- 
ing the relationship between executive functions and intelligence, learning or mastering reading and writing, however, suggest the utility of executive functioning data in the educational process (Hooper et al., 2002; Salthouse, 2005; Floyd et al., 2006; Garner, 2009; Duan et al., 2010; Shaul, Schwartz, 2014).

There are currently numerous theoretical perspectives on the nature, operation and the number of executive functions as well as many different tests that can be used as tools to identify and quantify them. Some theories focus on one isolated executive function, while others attempt to monitor several. Some tests map lower executive functions, while others focus on higher ones. The theoretical and methodological basis used differ to varying degrees. One of the most comprehensive surveys of testing methods can be found in the work of Strauss, Sherman and Spreen (2006). When our research team was considering which of the existing diagnostic measures to select to be adapted and standardised for use in Slovakia, two criteria played a crucial role: it had to be a test battery that would map a wide range of executive functions with more or less explicit affinity to a pupil's academic performance and, secondly, it had to be a measure that had worked well in countries with different socio-cultural characteristics. In light of these criteria, we finally selected the Delis-Kaplan system of executive functions: D-KEFS.

\section{D-KEFS Test Battery}

D-KEFS is a set of nine measures that can be used as a comprehensive system for mapping a wide range of higher and lower executive functions and cognitive processes in verbal and non-verbal domains. Although some of the executive functions occur in more than one measure, each of the measures has its own specifications and focus. Hence, D-KEFS does not provide a summary index (as, for instance, many intelligence tests do), and each individual test can be used specifically for the domain or problem area it represents. When designing the battery the authors (Delis, Kaplan, Kramer, 2001) took existing tests which they then systemically altered and enriched with tests which they designed themselves to extend the range of executive functions mapped.

Trail Making Test The first D-KEFS battery test is a modified version of the Trail Making Test originally developed back in the 1930's by Partington. In its present form, it consists of five subtests: visual search, arranging numbers, arranging letters, switching between numbers and letters and mo- 
tor speed. In each subtest, subjects are instructed to use pen or pencil to connect numbers or letters randomly distributed on a worksheet as fast as they can and in a set order. To solve the tasks, the subject has to activate a number of different cognitive processes. The executive functions involved include cognitive flexibility and inhibition. A range of primary and secondary indicators identify relevant executive functions. Many of these indicators are based on comparing performance in the fourth "critical" subtest with achievement in the remaining four subtests.

Verbal Fluency Test This test consists of three subtests. Within the time limit, the subjects are required to generate as many words as possible that begin with a designated letter (the first subtest), as many as possible that represent a particular semantic category (the second subtest) and, finally, as many as possible that switch between the two selected categories. As in the previous measure, there is also a range of primary and secondary indicators that can assess the characteristics of executive functions such as cognitive flexibility, response inhibition and verbal fluency.

Design Fluency Test The test is a nonverbal variation of the Verbal Fluency Test. The subject is required to create as many geometric shapes as possible according to the rules and within the time limit. The third subtest requires, as in the previous case, the subject to switch from one mode of behaviour to another. Thus the Design Fluency Test used a set of indicators to expose executive functions such as non-verbal fluency, response inhibition and cognitive flexibility.

The Color-Word Interference Test is a modified version of the famous Stroop test that maps a subject's ability to inhibit automated responses. A fourth subtest which requires the subject to switch between two different ways of responding to stimuli was added to the original three subtests by the authors of D-KEFS.

Sorting Test This is similar to the Wisconsin Card Sorting Test. Two sets of cards containing different perceptual and verbal characters are used as stimulus material. In the first subtest, the subject sorts the cards into two meaningful groups according to the properties of the characters on cards. In the second subtest, the subject is instructed to identify the rules the test administrator follows in order to sort the cards. This measure is primarily intended to identify characteristics such as the ability to solve problems, form concepts and think flexibly. 
The Twenty Questions Test was inspired by a popular game in which one of two players tries to guess, in as few questions as possible, what object (material object, living thing or idea) the other player has chosen. In this modified version, the subject is given a card with thirty ordinary objects (an aircraft, banana, spoon, and so on) which he or she has to identify with the help of as few yes-no questions as possible. The stimulus material is designed so as to allow for categorization and concept formation when guessing.

Tower Test The origins of this test can be traced back to the well-known Tower of Hanoi Test. The task is to build a structure identical to the printed model using a minimum number of moves according to the rules. This test maps spatial planning, the ability to learn the rules and the ability to inhibit impulsive reactions.

Words Context Test This test and the Proverb Test below together form a test pair developed by the D-KEFS authors to expand the battery so as to include tests that map the verbal domain of executive functioning. The subjects are presented with pseudo words (fictitious words) which they have to guess the meaning of with the help of graduated prompts. The test reveals skills such as deductive inference and flexibility of thinking. The Proverb Test consists of presenting eight proverbs to the subject. The subject is then required to interpret and explain the meaning of them. The test provides information on executive functions such as semantic integration and ability to generalise.

All nine tests were standardized by the authors using a stratified sample of 1,750 children, adolescents, and adults aged between 8 and 89 (Delis, Kaplan, Kramer, 2001). The sample was subsequently divided into 16 separate age groups with the number of subjects ranging from 75 to 175 for each group. As stated in the battery's original manual, the raw score of most of the test indicators showed a normal distribution and this was subsequently converted into a standard normal distribution with a mean of 10 and a standard deviation of 3 .

One of the primary objectives of this article is to illustrate, drawing on the example of the Slovak adaptation of D-KEFS battery, how complex and multifaceted it is to transfer psychological tests from one sociocultural environment to another. The second objective was to probe the potential for using the battery or part of it in the context of school education. Specifically, we examined the extent to which the values of the 
selected indicators in D-KEFS tests would be reflected in different groups of pupils with regard to their academic achievement and socio-cultural background.

\section{Slovak Adaptation of D-KEFS}

As mentioned above, unlike the previous tendency to view D-KEFS mainly as a tool for clinical psychological diagnosis, adapting the D-KEFS test battery for Slovakia was motivated by a desire to use it in teaching and in educational and psychological intervention. The selection of the standardisation samples and the process of providing evidence of the method's validity were conducted with this aim in mind.

The first step in the adaptation process was to translate the D-KEFS test battery into Slovak. While linguistically adapting the instructions for administering the test and for solving the tasks was essentially a routine process involving standard procedures, including back-translation, adapting some of the items from the verbal tests (Verbal Fluency Test, Sorting Test and Word Context Test) went beyond this. The challenge faced by the team working on the adaptation was not merely to preserve the formal semantic equivalence of the English original and the Slovak translation (denotative meaning of the terms). The adaptation had to ensure equivalence in the use of appropriate morphological and syntactical characters and the equivalence of connotations related to the culture of the respective countries. To successfully meet the above requirements, translators, linguists and psychologists collaborated on adapting the test items. The following are three examples which illustrate typical problems which had to be addressed during the process of adaptation:

The American original of the stimulus material in the first subtest of the Verbal Fluency Test includes the letters F, A, and S. The testee's task was to generate, within a time limit, as many words beginning with the first, then second and finally the third letter. On the face of it, it would seem that this would present no translation difficulties, since the English and Slovak alphabets are almost identical. However, the frequency with which these letters occur as initial letters in English words differs markedly from that in Slovak. The team, therefore, had to identify letters which occur with around the same frequency at the beginning of Slovak words as the English letters. So, instead of the original trio of letters, D, N, and K were selected. 
In the American original the Sorting Test includes a set of words which indicate various objects that can then be categorized either according to their semantic meaning (transport - animals, air - ground) or their morphology (one syllable - two syllables). Although the literal translation of the original words makes it possible to sort the words semantically, the translated equivalents differ in length from the original and could not therefore be sorted morphologically (English "car" vs Slovak "auto"; English "duck" vs. Slovak "kačica", and so on). It was therefore necessary to look again for words that would allow for both semantic and morphological equivalence.

In terms of the process of adaptation, the Word Context Test presented perhaps the biggest challenge. Here, it was necessary to modify not only the stimulus words (fictitious words) but also the set of prompts used to help identify the meaning of the words. For example, some of the English fictitious words were similar in form to actual Slovak words, which could a priori encourage the wrong semantic interpretation. One significant problem involved idiomatic expressions and phrases that occur in one language but have no counterpart in the other. For example, participants trying to identify the fictitious word "nelzen" (to make) are given the hint in English "Many people try to nelzen money". The verb "make" does not collocate with money in Slovak so there was no reason to use this hint. For the same reason, the analogical form "to make friends" could not be used in another hint. One of the major difficulties in adapting the English words was the different morphology. While many verbs and nouns in English are identical in form (for example "dance"), this is not the case in Slovak. Moreover, words take on different forms depending on the declination and conjugation (for example "tancovat" [to dance] - "tanec" [dance] - "tance" [dances]-"tancujeme" [we are dancing]).

\section{Standardisation Samples}

As mentioned above, the D-KEFS adaptation was carried out with the idea of using the test battery primarily in educational and psychological practice. The three standardisation samples were selected in keeping with this aim and focus. One of the crucial stages in the Slovak education system is the transition from the first (primary) stage to the second (junior secondary) stage. It is defined as the transition from fourth grade to fifth grade, which roughly occurs at age 9-11. The teacher generally assesses the child's individual performance against the performance of other pupils attending the same class; hence the pupil's actual age is only a secondary consideration. The basic criterion for selecting children for the standardization samples was the grade they attended. 
The basic standardization sample included 250 children attending regular fourth grade in primary schools in the selected locations of Košice and Prešov regions with respect to demographic characteristics relative to the population at their site of residence and the socioeconomic level of the family (147 girls and 103 boys, mean age of 9.7). More detail on the composition of the group in terms of gender and age is provided in Table 1.

Table 1

Composition of the standardisation sample in terms of gender and age

\begin{tabular}{|c|c|c|c|c|c|c|c|c|}
\hline \multirow{2}{*}{\multicolumn{3}{|c|}{$\begin{array}{l}8.06-8.11 \mathrm{yrs} \\
9-9.05 y r s\end{array}$}} & \multicolumn{5}{|c|}{ Age groups - six-monthly intervals } & \multirow[t]{2}{*}{ Total } \\
\hline & & & \begin{tabular}{|l|}
$9.06-$ \\
$9.11 \mathrm{yrs}$ \\
\end{tabular} & $\begin{array}{l}10- \\
10.05 y r s \\
\end{array}$ & $\begin{array}{l}10.06- \\
10.11 \mathrm{yrs} \\
\end{array}$ & & & \\
\hline \multirow{4}{*}{ gender } & \multirow{2}{*}{ girls } & $f$ & 19 & 39 & 43 & 33 & 13 & 147 \\
\hline & & $\%$ & $12.9 \%$ & $26.5 \%$ & $29.3 \%$ & $22.4 \%$ & $8.8 \%$ & $100.0 \%$ \\
\hline & \multirow{2}{*}{ boys } & $\mathrm{f}$ & 8 & 20 & 30 & 37 & 8 & 103 \\
\hline & & $\%$ & $7.8 \%$ & $19.4 \%$ & $29.1 \%$ & $35.9 \%$ & $7.8 \%$ & $100.0 \%$ \\
\hline \multirow{2}{*}{\multicolumn{2}{|c|}{$\begin{array}{l}\text { total } \\
\%\end{array}$}} & $f$ & 27 & 59 & 73 & 70 & 21 & 250 \\
\hline & & $10.8 \%$ & $23.6 \%$ & $29.2 \%$ & $28.0 \%$ & $8.4 \%$ & $100.0 \%$ & \\
\hline
\end{tabular}

The data obtained from this sample of children were used to develop norms but also to preliminary verify the reliability of the various D-KEFS tests and to gain an insight into the characteristics and the validity of the interpretations of the test results.

The reason for creating the other two samples of children was not to establish norms for other groups but to compare how the specific groups of pupils performed on D-KEFS in relation to the basic standardisation sample which is representative of the standard Slovak fourth-grade population.

The first of these specific groups comprised 50 Roma children (27 girls and 23 boys) with a mean age of 10.3. All the children in the sample came from socially disadvantaging backgrounds typical of Roma settlements in the Prešov region. Roma children are gradually increasing as a percentage of pupils in Slovak schools, moreover, pupils with significant problems with academic achievement. A closer look at their executive functioning could thus provide tools to help them in organising their schoolwork.

In contrast to this group there was also a sample of 55 children (17 girls and 38 boys) who attend special classes for gifted children in the Košice and Prešov regions. The children were the same age as their peers in the other 
two groups. Pupils who attend these classes are selected according to aboveaverage achievement criterion and the results of psychological assessment confirming above-average intellectual abilities.

\section{Procedures}

The prospective data collectors attended a training course in D-KEFS administration before data collection began. The course was attended by ten professional psychologists and twenty students studying master's degrees in psychology.

All three standardisation samples underwent the testing at school (in empty classrooms or staffrooms). Each child was tested individually and the average time taken to collect the data from a complete D-KEFS battery was around 80 to 90 minutes for each child. In the second session, after having undergone the D-KEFS battery, the children from the basic standardisation sample solved items from the Woodcock-Johnson (International Edition III) test battery. By contrast, after piloting a small sample of the Roma children, we decided to exclude the D-KEFS battery tests which the children had almost uniformly failed. The tests omitted were the Sorting Test, Words Context Test, Twenty Questions Test and the Tower Test.

\section{Results}

\section{Descriptive Characteristics of Selected Indicators}

When describing the D-KEFS battery above, we stated that for each test item dozens of primary and secondary indicators can be calculated. Reporting the standardisation results for each item in greater detail would exceed the conceptual framework and scope of this paper. Therefore, we have limited ourselves to only sixteen primary indicators of the tests solved by all three standardisation groups. The list of the selected primary indicators and an overview of their basic descriptive characteristics are summarised in Tables 2 and 3: 
Table 2

List of D-KEFS primary indicators analysed

\begin{tabular}{|l|l|l|}
\hline \multirow{4}{*}{ TEST } & \multicolumn{2}{|l|}{ PRIMARY INDICATOR } \\
\cline { 2 - 3 } & Symbol & Full Title \\
\hline \multirow{5}{*}{ TRAIL MAKING TEST } & P1 & Visual Search \\
\cline { 2 - 3 } & P2 & Number Sequencing \\
\cline { 2 - 3 } & P3 & Letter Sequencing \\
\cline { 2 - 3 } & P4 & Number-letter switching \\
\cline { 2 - 3 } & P5 & Motor Speed \\
\hline \multirow{5}{*}{ DERBAL FLUENCY TEST } & P6 & Letter Fluency: Total correct \\
\cline { 2 - 3 } & P7 & Category Fluency: Total correct \\
\cline { 2 - 3 } & P8 & Switching Fluency: Total correct responses \\
\cline { 2 - 3 } & P9 & Switching Fluency: Total correct switches \\
\hline INTERFERENCE TEST & P10 & Filled dots: Total correct \\
\cline { 2 - 3 } & P11 & Empty dots: Total correct \\
\cline { 2 - 3 } & P12 & Switching: Total correct \\
\cline { 2 - 3 } & P13 & Colour Naming \\
\cline { 2 - 3 } & P14 & Word reading \\
\cline { 2 - 3 } & P15 & Inhibition \\
\hline & & Inhibition and Switching \\
\hline
\end{tabular}

Table 3

Basic Descriptive Characteristics of D-KEFS Selected Primary Indicators

\begin{tabular}{|l|l|l|l|l|l|l|l|}
\hline indicator & sample & AP & s & skewness & kurtosis & Min. & Max. \\
\hline \multirow{4}{*}{ P1 } & standard & 30,92 & 9,53 &, $97^{*}$ & $1,12^{*}$ & 13 & 66 \\
\cline { 2 - 8 } & gifted & 29,48 & 8,02 & $.64^{*}$ & -.06 & 17 & 50 \\
\cline { 2 - 8 } & roma & 49.8 & 17.06 & $1.17^{*}$ & $1.95^{*}$ & 25 & 108 \\
\hline \multirow{4}{*}{ P2 } & standard & 51,35 & 18,39 & $1,19^{*}$ & $2,15^{*}$ & 20 & 120 \\
\cline { 2 - 8 } & gifted & 45.89 & 16.96 & $.728^{*}$ & .165 & 20 & 96 \\
\cline { 2 - 8 } & roma & 98.12 & 31.60 & .197 & -.944 & 40 & 150 \\
\hline \multirow{4}{*}{ P3 } & standard & 58,13 & 24,54 & $1,59^{*}$ & $3,03^{*}$ & 23 & 150 \\
\cline { 2 - 8 } & gifted & 46.89 & 20.35 & $2.59^{*}$ & $10.28^{*}$ & 19 & 146 \\
\cline { 2 - 8 } & roma & 138.58 & 28.05 & $-2.14^{*}$ & $4.38^{*}$ & 51 & 150 \\
\hline & standard & 116,19 & 45,78 &, $81^{*}$ &, 33 & 11 & 240 \\
\cline { 2 - 8 } & gifted & 90.63 & 28.50 & .55 & .52 & 35 & 165 \\
\cline { 2 - 8 } & roma & 234.74 & 20.46 & $-3.85^{*}$ & $13.51^{*}$ & 150 & 240 \\
\hline \multirow{3}{*}{ P5 } & standard & 58,97 & 31,93 & $1,22^{*}$ & $1,10^{*}$ & 15 & 150 \\
\cline { 2 - 8 } & gifted & 51.67 & 23.64 & .597 & -.882 & 20 & 105 \\
\cline { 2 - 8 } & roma & 88.90 & 35.87 & .376 & -1.223 & 28 & 150 \\
\hline
\end{tabular}




\begin{tabular}{|c|c|c|c|c|c|c|c|}
\hline \multirow{3}{*}{ P6 } & standard & 18,91 & 7,03 &, $58^{*}$ &, 21 & 4 & 44 \\
\hline & gifted & 21.11 & 6.70 & $.69^{*}$ & $1.60^{*}$ & 9 & 43 \\
\hline & roma & 6.44 & 4.24 & $1.63^{*}$ & $5.11^{*}$ & 1 & 24 \\
\hline \multirow{3}{*}{ P7 } & standard & 29,54 & 7,29 & , 16 & ,79* & 2 & 51 \\
\hline & gifted & 31.07 & 6.93 & -.26 & -.109 & 14 & 46 \\
\hline & roma & 15.36 & 4.68 & .64 & 1.06 & 6 & 30 \\
\hline \multirow{3}{*}{ P8 } & standard & 10,76 & 2,64 &,- 21 &, $82^{*}$ & 1 & 18 \\
\hline & gifted & 11.61 & 2.69 & $.79^{*}$ & 1.27 & .6 & 20 \\
\hline & roma & 5.50 & 2.24 & -.03 & .16 & 0 & 10 \\
\hline \multirow{3}{*}{ P9 } & standard & 9,02 & 3,11 &,$- 33^{*}$ & ,27 & 0 & 17 \\
\hline & gifted & 10.07 & 2.76 & $.95^{*}$ & $1.77^{*}$ & 5 & 19 \\
\hline & roma & 3.06 & 2.65 & .23 & -1.26 & 0 & 8 \\
\hline \multirow{3}{*}{ P10 } & standard & 6,79 & 2,33 &, 30 &,- 43 & 2 & 13 \\
\hline & gifted & 7.11 & 2.33 & .70 & -.20 & 4 & 13 \\
\hline & roma & 3.48 & 2.14 & $1.75^{*}$ & $6.80^{*}$ & 0 & 13 \\
\hline \multirow{3}{*}{$\mathrm{P} 11$} & standard & 7,40 & 2,47 &, $50^{*}$ &,- 03 & 2 & 16 \\
\hline & gifted & 7.63 & 2.60 & .52 & .11 & 3 & 15 \\
\hline & roma & 3.94 & 2.24 & $.80^{*}$ & .07 & 0 & 10 \\
\hline \multirow{3}{*}{$\mathrm{P} 12$} & standard & 5,44 & 1,97 &,- 01 &, 05 & 0 & 11 \\
\hline & gifted & 5.76 & 1.81 & $-.69^{*}$ & 1.27 & 0 & 10 \\
\hline & roma & 2.20 & 1.74 & .65 & -.01 & 0 & 7 \\
\hline \multirow{3}{*}{ P13 } & standard & 43,69 & 10,80 & $1,65^{*}$ & $3,48^{*}$ & 28 & 90 \\
\hline & gifted & 39.81 & 8.37 & .57 & -.08 & 25 & 61 \\
\hline & roma & 58.58 & 13.1 & $2.07^{*}$ & $7.81^{*}$ & 36 & 118 \\
\hline \multirow{3}{*}{ P14 } & standard & 34,72 & 8,99 & $1,58^{*}$ & $3,52^{*}$ & 20 & 72 \\
\hline & gifted & 31.83 & 6.52 & $1.70^{*}$ & $6.42^{*}$ & 22 & 61 \\
\hline & roma & 61.82 & 20.51 & .34 & $-1.40^{*}$ & 33 & 102 \\
\hline \multirow{3}{*}{ P15 } & standard & 84,62 & 26,19 & $1,34^{*}$ & $2,08^{*}$ & 40 & 180 \\
\hline & gifted & 74.26 & 22.70 & -.11 & .09 & 7 & 115 \\
\hline & roma & 102.34 & 35.56 & $1.00^{*}$ & .71 & 51 & 211 \\
\hline \multirow{3}{*}{ P16 } & standard & 88.65 & 25.00 & $1.30^{*}$ & $1.97^{*}$ & 48 & 178 \\
\hline & gifted & 82.11 & 21.74 & $.80^{*}$ & $1.32^{*}$ & 27 & 149 \\
\hline & roma & 132.52 & 33.05 & -.070 & -1.04 & 70 & 180 \\
\hline
\end{tabular}

One of the first things that stand out in Table 3 is the number of statistically significant skewed distributions and the statistically significant high kurtosis. In contrast to the allegedly normal distribution of indicators anticipated by the authors of the manual, fourteen of the sixteen primary indicators in our basic standardization group were statistically significantly skewed. The skewness values varied systematically from positive or nega- 
tive depending on whether the maximum score in the indicator pointed to high performance, such as the number of correct responses, a number of correctly formed pictures and the like (negative skewness) or whether, on the contrary, the maximum score indicated the lowest performance such as the time required to solve the problem (positive skewness). In principle, the same distribution pattern can be seen in the results attained by the gifted children. Tests to ascertain the normality of the distribution of the results attained by the two groups in relation to the indicators given confirmed that virtually all deviated significantly from normal distribution ( $p$-values for tests using the Shapiro-Wilk test varied in the standardization sample from $p<0.001$ to 0.028 ; hence, none of the values for the indicators exceeded the conventional level of $p=0.05$ ). In that Roma children group, the skewness of distributions, with a few exceptions, was not as significant as in the other two samples; some skewness in the opposite character even occurred sporadically. This phenomenon can be observed particularly in cases where the overwhelming majority of the Roma children completely or almost completely failed the indicator in question (for example, subtests with time limits). Otherwise, skewed characteristics in the sample of Roma children demonstrated similar tendencies as the other two samples. These results may be interpreted quite consistently: most of the indicators discriminate quite sensitively between "weak" performers, but "good" task solvers are lumped together. In terms of the test's psychometric qualities, this finding does not appear to be very positive. However, if we bear in mind that the DKEFS battery was primarily developed to detect and assist individuals who have problems, our findings are then consistent with the primary purpose for which the D-KEFS was designed.

\section{Between-group differences in D-KEFS}

The results in Table 3 also indicate the different results attained in the three samples of children. The statistical significance of the differences in the average scores in the individual variables was tested by one-way ANOVA followed by post-hoc tests (Bonferroni). Table 4 summarises the results: 
Table 4

One-way ANOVA Results for Evaluating Differences between Three Groups of Children in Selected D-KEFS Indicators

\begin{tabular}{|c|c|c|c|c|c|c|c|}
\hline $\begin{array}{l}\text { test } \\
\text { perfor- } \\
\text { mance } \\
\text { indicator }\end{array}$ & $\begin{array}{l}\text { sum of } \\
\text { squares }\end{array}$ & $\mathrm{df}$ & $\begin{array}{l}\text { mean } \\
\text { square }\end{array}$ & $\mathrm{F}$ & $\mathrm{p}$ & $\begin{array}{l}\text { partial } \\
\text { Eta } \\
\text { sq. }\end{array}$ & post hoc \\
\hline $\mathrm{P} 1$ & 15963.973 & 2 & 7981.987 & 69.598 & $<.001$ & .283 & $\mathrm{~A}>\mathrm{C} \quad \mathrm{B}>\mathrm{C}$ \\
\hline $\mathrm{P} 2$ & 95646.295 & 2 & 47823.147 & 112.997 & $<.001$ & .393 & $\mathrm{~A}>\mathrm{C} \quad \mathrm{B}>\mathrm{C}$ \\
\hline P3 & 297712.512 & 2 & 148856.256 & 249.029 & $<.001$ & .586 & $\mathrm{~A}>\mathrm{B}, \mathrm{C} B>\mathrm{C}$ \\
\hline $\mathrm{P} 4$ & 682413.017 & 2 & 341206.509 & 205.024 & $<.001$ & .538 & $\mathrm{~A}>\mathrm{B}, \mathrm{C} B>\mathrm{C}$ \\
\hline P5 & 44151.800 & 2 & 22075.900 & 22.423 & $<.001$ & .113 & $\mathrm{~A}>\mathrm{C} \quad \mathrm{B}>\mathrm{C}$ \\
\hline $\mathrm{P} 6$ & 7338.256 & 2 & 3669.128 & 82.979 & $<.001$ & .320 & $\mathrm{~A}>\mathrm{C} \quad \mathrm{B}>\mathrm{C}$ \\
\hline $\mathrm{P} 7$ & 9133.861 & 2 & 4566.931 & 95.109 & $<.001$ & .351 & $\mathrm{~A}>\mathrm{C} \quad \mathrm{B}>\mathrm{C}$ \\
\hline P8 & 1284.046 & 2 & 642.023 & 95.210 & $<.001$ & .351 & $\mathrm{~A}>\mathrm{C} \quad \mathrm{B}>\mathrm{C}$ \\
\hline $\mathrm{P9}$ & 1656.358 & 2 & 828.179 & 91.738 & $<.001$ & .343 & $\mathrm{~A}>\mathrm{C} \quad \mathrm{B}>\mathrm{C}$ \\
\hline $\mathrm{P} 10$ & 489.870 & 2 & 244.935 & 46.334 & $<.001$ & .208 & $\mathrm{~A}>\mathrm{C} \quad \mathrm{B}>\mathrm{C}$ \\
\hline $\mathrm{P} 11$ & 529.090 & 2 & 264.545 & 43.842 & $<.001$ & .199 & $\mathrm{~A}>\mathrm{C} \quad \mathrm{B}>\mathrm{C}$ \\
\hline $\mathrm{P} 12$ & 466.474 & 2 & 233.237 & 63.185 & $<.001$ & .264 & $\mathrm{~A}>\mathrm{C} \quad \mathrm{B}>\mathrm{C}$ \\
\hline $\mathrm{P} 13$ & 11148.048 & 2 & 5574.024 & 47.704 & $<.001$ & .213 & $\mathrm{~A}>\mathrm{B}, \mathrm{C} B>\mathrm{C}$ \\
\hline $\mathrm{P} 14$ & 33189.388 & 2 & 16594.684 & 135.948 & $<.001$ & .436 & $\mathrm{~A}>\mathrm{C} \quad \mathrm{B}>\mathrm{C}$ \\
\hline $\mathrm{P} 15$ & 21283.199 & 2 & 10641.600 & 14.400 & $<.001$ & .076 & $\mathrm{~A}>\mathrm{B}, \mathrm{C} B>\mathrm{C}$ \\
\hline $\mathrm{P} 16$ & 88964.528 & 2 & 44482.264 & 66.667 & $<.001$ & .275 & $\mathrm{~A}>\mathrm{C} \quad \mathrm{B}>\mathrm{C}$ \\
\hline
\end{tabular}

$\mathrm{A}=$ basic standardisation sample $\mathrm{B}=$ gifted $\mathrm{C}=$ Roma children

It follows from the results that statistically significant differences between the samples of children are observable in all the primary variables, while the size of the effect is medium to large in all groups. The results of the post-hoc tests indicate that in all cases the differences are related to the group of Roma children. Their results differed significantly from the results of the basic standardization sample and from the results attained by the gifted children. In other words, the average performance of these children was systematically lower than the performance of their peers in the other two samples. In contrast, statistically significant differences between the standardisation sample and the sample of gifted children were found in only four of the sixteen indicators. These findings suggest that it is more appropriate to refer to special norms in diagnosing executive functions in Roma children. This was the next step in our standardisation. 


\section{Comparison of standardised norms for Slovak, American and Roma pupils}

Despite finding that the majority of the primary indicator distributions in all three groups of children manifested significant skewness rather than normal distribution, we proceeded to the next step in adapting D-KEFS for Slovakia, that is, to developing standardised norms using the same format as the American original $(\mu=10, \sigma=3)$. One reason for this is that it enables us to compare US standards of performance with that of Slovak and Roma pupils. Table 5 presents raw scores for the individual indicators corresponding to the relevant standard scores for American, Slovak and Roma pupils. For the sake of clarity, we have selected only the central value ( $S S=$ 10) and two values distant from the central value by $\pm 2.5 z$ ( $S S=3$ and $S S=$ 17) from all the values of the standard score. Since the US standardisation established separate norms for the groups of 9 year olds and 10 year olds, to enable comparison with our groups we used the average of the central values of the raw scores of both age groups.

Table 5

Raw Score of 16 D-KEFS Indicators Attributable to Standardised Score 3, 10 and 17: US, Slovak and Roma Samples (aged 9-10)

\begin{tabular}{|l|l|l|l|l|l|l|l|l|l|}
\hline \multirow{2}{*}{$\begin{array}{l}\text { test per- } \\
\text { formance } \\
\text { indicator }\end{array}$} & \multicolumn{9}{|l|}{ standardised score } \\
\cline { 2 - 12 } & US sample & \multicolumn{3}{l|}{ Slovak sample } & \multicolumn{3}{l|}{ Roma sample } \\
\cline { 2 - 12 } & 3 & 10 & 17 & 3 & 10 & 17 & 3 & 10 & 17 \\
\hline P1 & 52 & 33 & 10 & 60 & 29 & 15 & 106 & 48 & 24 \\
\hline P2 & 95 & 69 & 10 & 112 & 49 & 22 & 150 & 98 & 26 \\
\hline P3 & 86 & 48 & 10 & 143 & 51 & 23 & --- & 150 & 49 \\
\hline P4 & 215 & 122 & 23 & 238 & 104 & 24 & --- & --- & 153 \\
\hline P5 & 86 & 42 & 2 & 150 & 49 & 17 & 150 & 78 & 24 \\
\hline P6 & 4 & 21 & 38 & 5 & 18 & 37 & --- & 7 & 16 \\
\hline P7 & 9 & 27 & 44 & 12 & 30 & 48 & 4 & 16 & 26 \\
\hline P8 & 4 & 9 & 15 & 3 & 11 & 17 & 0 & 5 & 11 \\
\hline P9 & 1 & 8 & 15 & 0 & 8 & 16 & --- & 4 & 11 \\
\hline P10 & 0 & 7 & 13 & 1 & 7 & 13 & -- & 3 & 9 \\
\hline P11 & 0 & 7 & 13 & 2 & 7 & 14 & --- & 3 & 10 \\
\hline P12 & 0 & 5 & 9 & 0 & 5 & 10 & -- & 2 & 7 \\
\hline P13 & 66 & 44 & 22 & 84 & 41 & 29 & 91 & 57 & 35 \\
\hline P14 & 54 & 33 & 12 & 66 & 33 & 18 & 98 & 55 & 21 \\
\hline P15 & 153 & 93 & 35 & 173 & 79 & 46 & --- & 92 & 42 \\
\hline P16 & 150 & 93 & 38 & 178 & 83 & 50 & --- & 128 & 63 \\
\hline & & & & & & & & & \\
\hline
\end{tabular}


The results in Table 5 show systematic high similarity - or, in many cases, even uniformity - in the norms for American and Slovak children both in the centre of the performance spectrum as well as at the edges. However, comparison with the norms for Roma children shows a significantly different picture. In many instances, particularly in solving tasks with speed limits, more than half the Roma children failed the given time limit; consequently the raw score distribution was skewed so much that the norms for standardised score started at around the value of ten. This is illustrated for example by indicators P3 and P4 where only $20 \%$ and $8 \%$ of the subjects, respectively, managed to solve the task within the time limit. It is therefore quite understandable that the norms for Roma children are much softer, especially in the lower and middle range of performance. Many achievements in the group of Roma children assessed by a standard score of around the value of ten, if assessed with reference to US or Slovak norms, would match with the results even two standard deviations below the average. Interestingly, however, the distances between Slovak and American norms on the one hand and Roma norms on the other are not constant at each level of performance. In many cases it is possible to observe a smaller yet significantly greater convergence towards the upper (superior, in terms of performance) range of the norms. In other words, while the differences in performance between subnormal Slovak and Roma children are quite pronounced, with more advanced performance the differences often decrease and above-average performers in the Slovak and Roma children groups do not differ that much. This is particularly true for test items where the subjects least rely on previously acquired knowledge or language proficiency. The above is illustrated in Figure 1 and Figure 2: 


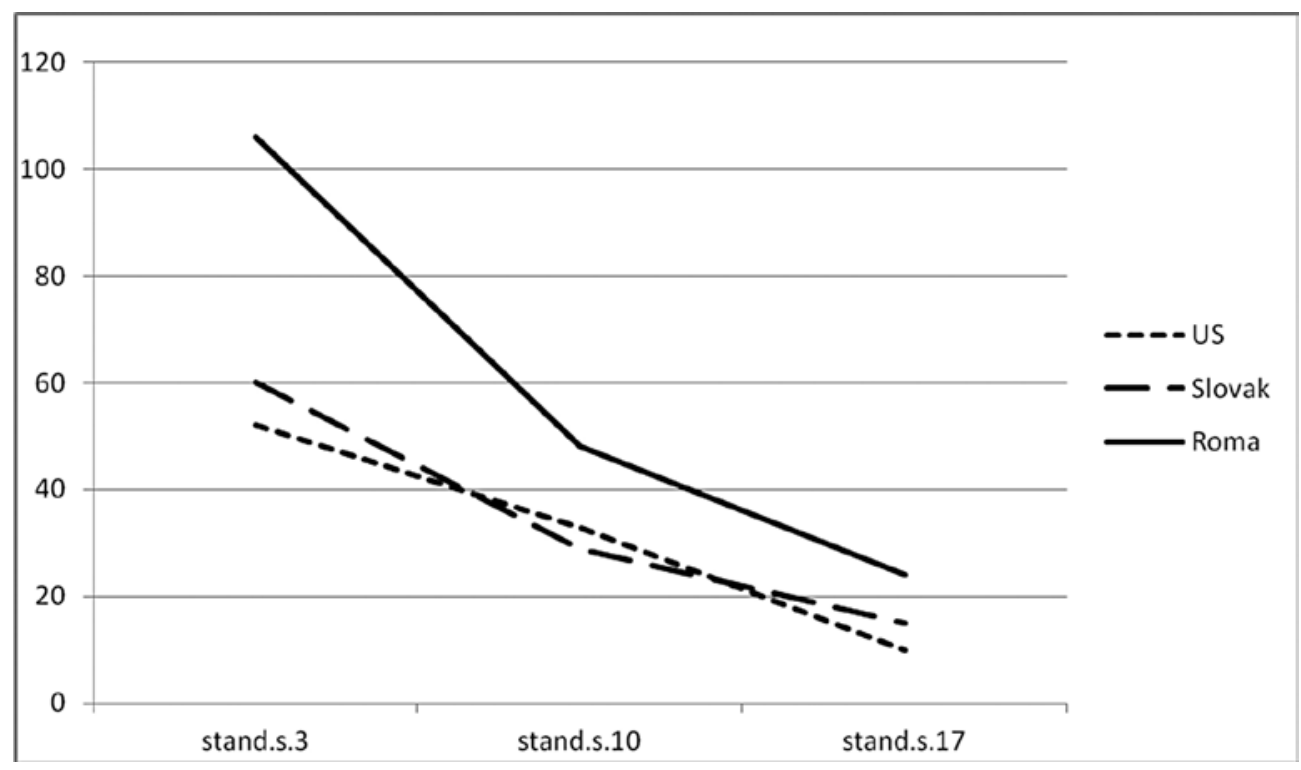

Figure 1: Comparison of US, Slovak and Roma Norms in Three Performance Levels (Standard Score 3, 10 and 17) for Indicator P1: Trail Making Test Visualisation

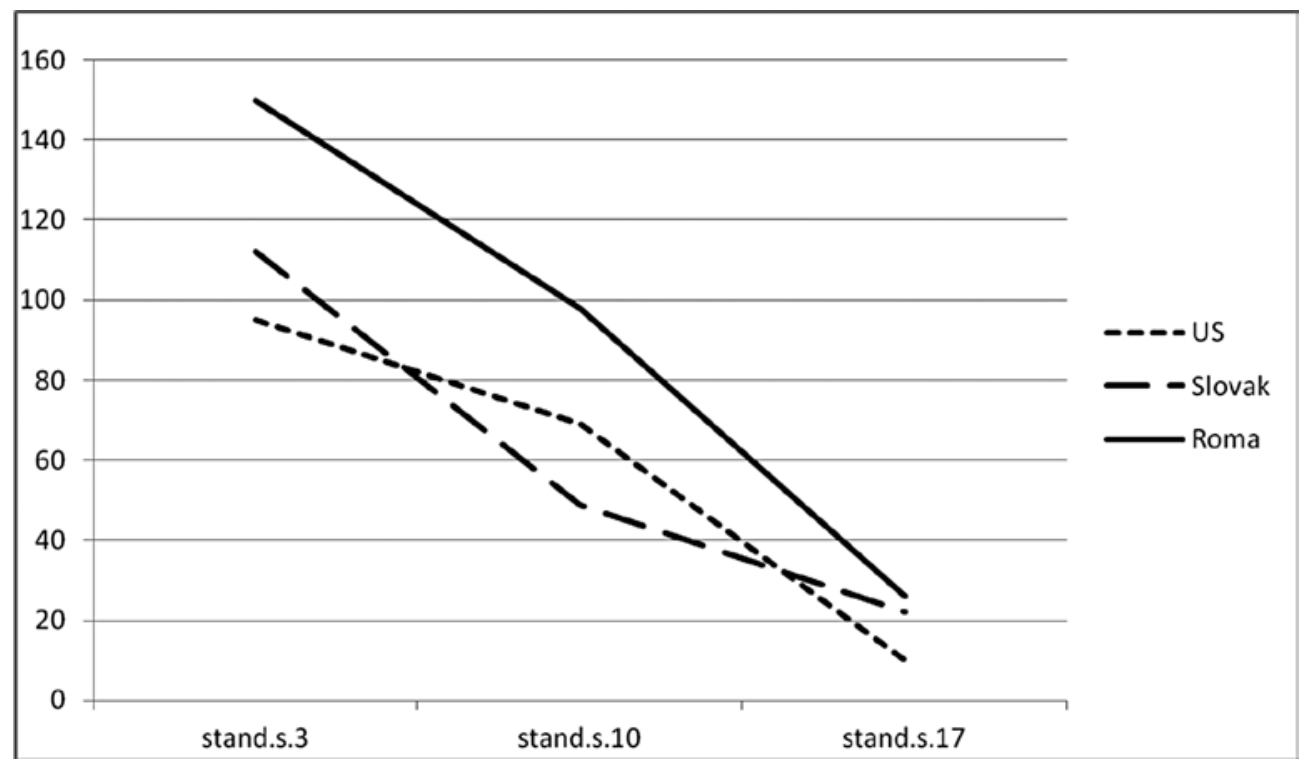

Figure 2: Comparison of US, Slovak and Roma Norms in Three Performance Levels (Standard Score 3, 10 and 17) for Indicator P2: Trail Making Test Ordering Numbers 


\section{Discussion}

The paper attempted to depict selected aspects of D-KEFS adaptation in Slovakia. Despite the generally agreed theoretical premise that adapting a test from one socio-cultural environment to another should involve more than just mechanical translation (Hambleton, de Jong, 2003), in reality, this premise is often neglected. Drawing on the example of our adaptation process, we want to illustrate how multidisciplinary and often complex is the process of converting the test content not just to another language but also to a different culture. In this regard, our experience confirms that the adapting cognitive tests is a process that has to take place on several qualitatively different levels (Malda et al., 2008) and, multidisciplinary cooperation is therefore necessary for it to succeed.

The descriptive analysis of the data collected from the three samples of children aged 9-10 highlights the important difference between the American results and ours. We found it surprising that while in our relatively large basic standardisation sample $(n=250)$ the distributions of numerous test indicators differed significantly from normal distribution (as well as in the remaining two samples), the authors of the American manual report normal distributions of raw scores for their samples that consisted mostly of much smaller numbers of people (usually around $n=70$ ) (Delis, Kaplan and Kramer, 2001). This finding has two implications for further work on the test battery. First, at least in the case of Slovak fourth-graders, the battery is more appropriate for assessing children who perform weakly, since these are the kind of pupils that the tests differentiate with adequate sensitivity. Second, our findings show the use of standardised scores is optimal. Where the distribution is significantly different from normal, percentile norms would perhaps be more appropriate.

One of the original motivations for choosing to adapt D-KEFS to the Slovak setting was the intention to use the battery as a tool for working with Roma pupils. Numerous studies have shown that Roma children achieve significantly lower results in traditional intelligence tests in comparison with children from the majority population (Ferjenčik, Bačová, Bányaová 1994; Rushton et al., 2007; Ferjenčík 2009; Čvorovic, Lynn, 2014). A comparison of the respective performance of majority Slovak children and their Roma peers on the selected D-KEFS primary indicators proved that what intelligence test have systematically shown also applies to this test battery. However, it has also been revealed that this difference is not attributable primarily to executive functions but rather to the socio-cultural disadvan- 
tages affecting these children. The greatest differences are in fact manifested in tasks that require reliable mastery and control of routine skills such as reading or the acquisition of a standard vocabulary. For deeper insight into the executive functioning of these children further analysis of secondary and also primary indicators will be needed in the future, in particular various difference scores and composite scores that could be used to eliminate, to some extent, the negative socio-cultural impact.

Finally, setting norms for Roma children and comparing them with those for the majority Slovak population has produced yet another finding. Since many of the D-KEFS tests were difficult for Roma children, this sample of children manifested a distribution skewed to the opposite of that of the majority population sample. Many tests from the battery discriminated well between a weaker performance and slightly above-average performance in the majority population. With Roma children this was often the opposite, thus above-average performing children could be identified more clearly and distinctly. This led to the idea of using selected D-KEFS tests in the future, after necessary verification, as tools to select Roma children who have the cognitive potential to attain greater academic success in education.

\section{References}

Alvarez, J. A., \& Emory, E. (2006). Executive function and the frontal lobes: A metaanalytic review. Neuropsychology Review, 16(1), 17- 41.

Anderson, V., Jacobs, R., \& Anderson, P. (Eds). (2008). Executive functions and the frontal lobes: A lifespan perspective. New York: Psychology press

Baddeley, A., \& Hitch, G. (1974). Working memory. In G. H. Bower (Ed.), Recent advances in learning and motivation (Vol. 8). New York: Academic.

Barkley, R. A. (2012). Executive functions: what they are, how they work, and why they evolved. New York: Guilford.

Brody, N. (1997). Intelligence, schooling, and society. American Psychology, 52(10), 1046-1050.

Brody, N. (1999). What is intelligence? International Review of Psychiatry, 11(1), 19-25. Butler, S. R., Marsh, H. W., Sheppard, M. J., \& Sheppard, J. L. (1985). Seven-year longitudinal study of the early prediction of reading achievement. Journal of Educational Psychology, 77, 349-361.

Čvorovic, J., \& Lynn, R. (2014). Intelligence and reproductive success of Bosniaks, Serbs and Roma in Serbia. Mankind Quarterly, 54(3), 434-446.

Delis, D. C., Kaplan, E., \& Kramer, J. H. (2001). Delis-Kaplan executive function system (D-KEFS). San Antonio: The Psychological Corporation.

Dillon, D. G., \& Pizzagalli, D. A. (2007). Inhibition of action, thought and emotion: A selective neurobiological review. Applied and Preventive Psychology, 12(3), 99-114. 
Duan, X., Wei, S., Wang, G., \& Shi, J. (2010). The relationship between executive functions and intelligence on 11 to 12-year-old children. Psychological Test and Assessment Modelling, 52(4), 419-431.

Duncan, J., Emslie, H., Williams, P., Johnson, R., \& Freer, C. (1996). Intelligence and the frontal lobes: The organization of goal-directed behavior. Cognitive Psychology, 30, 257-303.

Elliot, R. (2003). Executive functions and their disorders. British Medical Bulletin, 65(1), 49-59.

Floyd, R., McCormack, A., Ingram, E. L., \& Davis, A. (2006). Relations between the Woodcock-Johnson III clinical clusters and measures of executive functions from the Delis-Kaplan executive function system. Journal of Psychoeducational Assessment, 24(4), 303-317. Ferjenčík, J., Bačová, L., \& Bányayová, T. (1994). Kvantitativne a kvalitativnne rozdiely v riešení farebných progresivnych matíc slovenskými a rómskymi deṫmi. Psychológia a patopsychológia dietááa, 29(1), 9-26.

Ferjenčik, J. (2009). Diagnostika inteligencie rómskych detí. Prevencia, 8, 28-37.

Garner, J., K. (2009). Conceptualizing the relations between executive functions and self-regulated learning. Journal of Psychology, 143(4), 405-426.

Godefroy, O., Cabaret, M., Petit-Chenal, V., Pruvo, J.-P., \& Rousseaux, M. (1999). Control functions of the frontal lobe: Modularity of the central-supervisory system. Cortex, 35, 1-20.

Hambleton, R. K., \& De Jong, J. (Eds). (2003). Advances in translating and adapting educational and psychological tests. Language testing, 20(2), 127-240.

Hooper, S. R., Schwartz, C. W., Wakely, M. B., Kruif, R. L., \& Montgomery, J. W. (2002). Executive functions in elementary school children with and without problems in written expression. Journal of Learning Disabilities, 35(1), 57-68.

Jensen, A. R. (1998). The g factor. Westport: Praeger.

Keith, T. Z. (1999). Effects of general and specific abilities on student achievement. School Psychology Quarterly, 14(3), 239-262.

Koven, N. S., \& Thomas, W. (2010). Mapping facets of alexithymia to executive dysfunction in daily life. Personality and Individual Differences, 49, 24-28.

Lezak, M. D. (1983). Neuropsychological assessment (2nd ed.). New York: Oxford University Press.

Malda, M., Van de Vijver, F. R., Srinivasan, K., Transler, C., Sukumar, P., \& Rao, K. (2008). Adapting a cognitive test for a different culture: An illustration of qualitative procedures. Psychology Science Quarterly, 50(4), 451-468.

McCloskey, G., Perkins, A., \& Van Divner, B. (2008). Assessment and intervention for executive function difficulties (School-based practice in action). New York, Taylor \& Francis: Routledge.

Miyake, A., Friedman, N., Emerson, M., Witzki, A., \& Howerter, A. (2000). The unity and diversity of executive functions and their contributions to complex "frontal lobe" tasks: A latent variable analysis. Cognitive Psychology, 41, 49-100.

Rapp, M., \& Reischies, F. (2005). Attention and executive control predict Alzheimer's disease in late life: Results from the Berlin Aging Study (BASE). Journal of Geriatric Psychiatry, 13, 134-141.

Rushton, J. P., Čvorovič, J., \& Bons, T. (2007). General mental ability in South Asians: Data from three Roma communities in Serbia. Intelligence 35(1), 1-12. 
Salthouse, T. (2005). Relations between cognitive abilities and measures of executive functioning. Neuropsychology, 19(4), 532-545.

Shaul, S., \& Schwartz, M. (2014). The role of the executive functions in school readiness among preschool-age children. Reading and Writing, 27(4), 749-768.

Strauss, E., Sherman, E. M. S., \& Spreen, O. (2006). A compendium of neuropsychological tests: Administration, norms and commentary (3rd ed.). New York: Oxford University Press.

Stuss, D. (2011). Functions of frontal lobes: Relation to executive functions. Journal of International Neuropsychological Society, 17, 759-765.

Stuss, D., Alexander, M., P. (2000). Executive functions and the frontal lobes: A conceptual view. Psychological Research, 63, 289-298.

\section{Authors:}

Ján Ferjenčík, Asociate Professor

Pavol Jozef Safarik University

Faculty of Arts

Department of Psychology

Moyzesova 9

04001

Košice

Slovakia

Email: jan.ferjencik@upjs.sk

Miriam Slavkovská, Ph.D.

Pavol Jozef Safarik University

Faculty of Arts

Department of Psychology

Department of Psychology

Moyzesova 9

04001

Košice

Slovakia

Email: miriam.slavkovska@upjs.sk

Juraj Kresila, Ph.D.

Prešovská univerzita v Prešove

Pedagogická fakulta

Katedra komunikačnej a literárnej výchovy

UI. 17. novembra 15

08001

Prešov

Email: juraj.kresila@unipo.sk 